Canadian Journal of Fisheries and Aquatic Sciences

Canadian Science Publishing

Journal canadien des sciences halieutiques et aquatiques

\title{
Limited functional responses of plankton food webs in northern lakes following diamond mining
}

\begin{tabular}{|r|l|}
\hline Journal: & Canadian Journal of Fisheries and Aquatic Sciences \\
\hline Manuscript ID & cjfas-2016-0418.R1 \\
\hline Danuscript Type: & Article \\
\hline Complete List of Authors: & $\begin{array}{l}\text { St-Gelais, Nicolas; Universite du Quebec a Montreal, Department of } \\
\text { Biological Sciences } \\
\text { Jokela, Anneli; ERM Consultants Ltd. ; Wek'èezhìi Land and Water Board } \\
\text { Beisner, Beatrix; Université du Québec à Montréal, }\end{array}$ \\
\hline Keyword: & functional ecology, nitrate, PLANKTON < Organisms, mining \\
\hline \multicolumn{2}{|c}{} \\
\hline
\end{tabular}




\title{
Limited functional responses of plankton food webs in northern lakes following diamond mining
}

\author{
Nicolas F. St-Gelais ${ }^{1 *}$, Anneli Jokela ${ }^{2,3}$ and Beatrix E. Beisner ${ }^{1}$ \\ ${ }^{1}$ Department of Biological Sciences and Groupe de Recherche Interuniversitaire en Limnologie \\ et en Environnement Aquatique (GRIL), University of Québec at Montréal, C.P. 888 Succ. \\ Centre-Ville, Montréal, QC, H3C 3P8, Canada \\ ${ }^{2}$ ERM Consultants Ltd. Suite 201, $512049^{\text {th }}$ Street, Yellowknife, NT, X1A 1P8. \\ ${ }^{3}$ Present Address: Wek'èezhìi Land and Water Board. \#1 $490528^{\text {th }}$ Street, Yellowknife, NT, \\ X1A 3S3. \\ * Corresponding author: Nicolas F. St-Gelais (nicolas.fstgelais@gmail.com)
}


There is a very limited understanding of the impact of diamond mining on the aquatic

3 communities of lakes that receive mine activity residue. For aquatic communities, assessing the

4 response to mining, which can affect multiple variables concurrently, is not trivial, especially

5 when a species-by-species approach is used. Thus, we assessed diamond mine impacts using

6 changes in plankton functional composition enabling an integrated evaluation of the ecological

7 responses of aquatic ecosystems. Using a 19-year dataset, we evaluated the functional responses

8 of lake phytoplankton and zooplankton to water quality changes associated with mining activities

9 in five downstream lakes of the Ekati diamond mine (NWT, Canada). Our results demonstrate

10 that diamond mine activity shifted phytoplankton functional composition toward edible diatoms,

11 and more recently the rotifer communities toward parallelepiped types, while for crustacean

12 zooplankton we observed a reinforcement of the original functional composition. Following

13 functional, rather than taxonomic changes enabled a more mechanistic understanding of the

14 processes behind the impacts and should facilitate the generalization of impacts to other sites,

15 permitting comparison of community shifts with other mining types.

16 Keywords: phytoplankton; zooplankton; functional ecology; nitrate enrichment; mining; northern

17 lakes; water quality; Northwest Territories, Canada; rotifer; crustacean 


\section{Introduction}

Mining activities in northern Canada have steadily increased over recent decades, and are expected to further grow by $91 \%$ between 2011 and 2020 (The Conference Board of Canada 2013). Diamond mining has played an important role in recent expansion, with Canada becoming one of the main diamond producers in the world. Expansion is expected to continue as several new mining projects (e.g. Renard Project in Quebec, Jay Pipe at Ekati in the NWT) start operations within the next few years. As many different compounds are exported from a diamond mine to neighboring lakes (ERM 2014), understanding the effects of such mining activities on water quality and consequently on surrounding ecosystems is crucial to minimize their impact, as well as to comply with federal, provincial and territorial laws on environmental protection.

In lakes, plankton are trophically important organisms as they largely control the flux of energy and matter in mostly unproductive northern ecosystems (Kling et al. 1992; Gu et al. 1994, 1996). Consequently, mining effects on plankton should ultimately also have repercussions for the functioning of lake ecosystems, including higher trophic levels (e.g. fish). Moreover, as they have short generation times, plankton communities respond quickly to disturbances and are thus useful indicators to track environmental change, in addition to providing important insights on the general response of aquatic ecosystems (Whitton et al. 1991; Carvalho et al. 2013; Khalifa et al. 2015).

The Ekati Diamond Mine is Canada's first diamond mine and has been in operation since 1998. This study was conducted in the Koala Watershed, one of the main watersheds influenced by the Ekati Diamond Mine. As a component of the Ekati Diamond Mine Aquatic Effects Monitoring Program (AEMP), phytoplankton and zooplankton communities in Koala Watershed 
41 lakes were sampled annually over 19 years, including two years before mining operations began,

42 along with multiple water quality parameters and physical variables. We used these time-series

43 to study how temporal changes in water quality impacted downstream plankton communities.

44 We used a functional trait perspective for interpreting temporal community changes; specifically, we tracked changes in functional trait composition. Using a functional approach enabled us to establish a more general and mechanistic evaluation of the ecological response of lakes to mining activities with conclusions that could be more easily applied to other locations without reference to taxonomic detail. This approach is also likely to be more amenable to industry or other stakeholders, requiring less taxonomic expertise if easily attributed traits provide the same information as more taxonomically-based approaches; saving time and money but still permitting

51 valid environmental impact assessments. However, the correspondence of taxonomic and 52 functional conclusions remains to be verified and was thus one of the goals of this study. from a mine to the environment. Through such releases, increased concentrations of some trace elements (e.g. copper, aluminium) could have toxic effects on living organisms (see AEMP

57 appendix G, ERM 2014). However, it was previously determined that in the Koala Watershed, interaction of species within plankton food webs; affecting composition and diversity, with such

62 effects being well established in the ecological literature, especially for phosphorus (Downing \& 63 McCauley 1992; Jeppesen et al. 2000a,b; Barnett \& Beisner 2007; Orihel et al. 2012; Monchamp 
64 et al. 2014). In terms of macronutrients, nitrogen $(\mathrm{N})$, mainly in the form of nitrate $\left(\mathrm{NO}_{3}\right)$, is one

65 of the main nutrient inputs to lakes of the Koala Watershed as a result of mining activities, and

66 more specifically from blast residue. Nitrogen inputs thus typically occur without addition of

67 phosphorus (P), leading to a change in the N:P ratio in lakes, which in itself should have

68 important effects on plankton communities (Saros et al. 2012; Saros \& Anderson 2015). For

69 example, the global shift toward a greater propensity for cyanobacteria blooms in lakes has been

70 attributed not only to increases in macronutrient concentrations, but to altered N:P ratios (Paerl

71 \& Otten 2013). Changes in phytoplankton composition in response to altered macronutrient

72 stoichiometry should also trigger changes at the primary consumer (i.e. zooplankton) trophic

73 level, and eventually potentially to higher trophic levels (e.g. fish), which respond to changes in

74 size structure, quality or overall quantity of zooplankton.

75 We examined the impact of almost two decades of mining activity on the northern lake 76 plankton communities downstream from Canada's first diamond mine using 19 years time series

77 across five impacted and two reference lakes. We wanted to determine whether there has been a 78 significant effect of mining activities, via water quality changes, on plankton functional 79 composition, and to identify the drivers of community change.

\section{$81 \quad$ Materials and methods}

$82 \quad$ Study design and sampling

The Ekati Diamond Mine is located $100 \mathrm{~km}$ north of the tree line in the Canadian

84 subarctic $(64.71 \mathrm{~N}, 110.62 \mathrm{~W}$, Northwest Territories) on a landscape of interconnected wetlands

85 and lakes (Figure 1, Table1). Lakes in this watershed (Koala) are generally clear with low 
nutrient concentration and low productivity (Rescan 2012). This study was conducted in five monitored lakes of the Koala Watershed, downstream of the mine's Long Lake Containment Facility (LLCF), which receives mining by-products such as processed kimberlite, as well as all water that has been used in mining activities. The LLCF is considered to be the main influence of the mine on the surrounding aquatic environment, as water meeting regulatory effluent criteria is periodically discharged downstream into Leslie Lake (Rescan 2012). Consequently, we expected to observe a decrease in detectable mine effects through the downstream watershed, as distance from the LLCF increased. To do so, we divided monitored lakes in two categories: lakes that were proximal to the LLCF (Leslie and Moose) and distal lakes (Nema, Slipper and S2). We compared the monitored Koala Watershed lakes to two reference lakes outside of the Koala Watershed to track natural temporal trends in subarctic lakes.

Plankton communities were sampled annually (from 1996 to 2014 in most lakes, including two pre-operational years), in early August, at the deepest point in each lake. Phytoplankton were sampled at $1 \mathrm{~m}$ water depth with a Teflon-lined General Oceanics FLO bottle (GO-FLO; 5 L) and whole water samples were preserved in Lugol's iodine solution. Zooplankton (crustacean and rotifer) were sampled using vertical hauls of a conical $118 \mu \mathrm{m}$ mesh net ( $0.3 \mathrm{~m}$ diameter) equipped with a General Oceanics flowmeter (Model 2030R). Zooplankton were preserved in 5\% buffered formalin (final concentration). For phytoplankton and zooplankton, three samples were collected and analysed separately, with data then averaged for further analyses. Zooplankton counts were done on a series of $1 \mathrm{ml}$ subsample aliquots that were counted sequentially until the target count of between 200 and 400 crustacean and rotifer zooplankton were identified. Organisms were identified to the most highly resolved taxonomic level possible. For phytoplankton, the volume of sample enumerated was dependent on overall 
109 cell densities. The subsample was mixed and allowed to settle in an Utermohl-type settling

110 chamber for approximately 24 hours and then examined and enumerated at $630 \times$ magnification

111 using an inverted Leica microscope. Phytoplankton were identified to the lowest practical taxon

112 using the transect method until at least 300 natural counting units were enumerated. For colonial

113 algae, each colony was counted as one natural unit and cell numbers in each unit were recorded,

114 or in the case of filaments, each filament was counted as one natural unit and the cell numbers of

115 each filament were recorded (for details see ERM 2014).

116 Environmental variables were measured at the same time as the plankton sampling.

117 Water quality samples were collected at $1 \mathrm{~m}$ water depth using an acid-cleaned, Teflon-lined

118 General Oceanics FLO bottle. All water quality samples were sent to ALS Global (Yellowknife,

119 NWT) for analyses of water quality variables at the lowest available detection limit (for details 120 see ERM 2014).

121 Response variables: Functional composition

122 The overarching objective of this study was to use a functional trait approach (functional 123 composition) to understand the ecological implications of observed changes in the plankton 124 communities of monitored lakes in the Koala Watershed, as well as the reference lakes. The 125 selection of functional traits was thus critical for obtaining ecologically meaningful results.

126 Selected traits for phytoplankton and zooplankton (rotifer and crustacean) were chosen to reflect 127 how organisms interact with their environment (response or effect traits, see Hooper et al. 2005).

128 Thus, we selected traits related to resource acquisition (e.g. pigment type, feeding strategy) and 129 predation avoidance strategies (e.g. motility, relative swimming speed), as these functional traits 130 are those that establish the trophic relationships in food webs, including responses to nutrient 131 enrichment (Table 2). Phytoplankton trait values were obtained from the literature (see Longhi 
132 and Beisner 2010 for details) and included traits related primarily to resource acquisition: (i)

133 capacity for $\mathrm{N}$-fixation, (ii) silica demand, (iii) capacity for mixotrophy, (iv) pigment

134 composition; and to predator avoidance: (v) cell motility and (vi) edibility to zooplankton (<

$13535 \mu \mathrm{m}$ maximum linear dimension) and (vii) tendency to form colonies. Crustacean zooplankton

136 traits values were also obtained from the literature (see Barnett, Finlay, \& Beisner 2007) and

137 included (i) feeding type, (ii) trophic group and (iii) relative swimming speed (RSS, categorical

138 variable from 0 to 6 with 0 being relatively non-motile). Information on functional traits for

139 rotifers is very limited relative to phytoplankton and crustacean zooplankton; the only available

140 for comparison were morphological traits related to predator avoidance (see McCauley 1984): (i)

141 shape, (ii) the presence of a spine and (iii) tendency to form colonies. With these traits, we

142 estimated functional composition as our measure of functional change. Phytoplankton biomass

143 was estimated from biovolumes using cell and colony dimensional length measurements and

144 corresponding geometrical forms (Hillebrand et al. 1999). Zooplankton (rotifer and crustacean)

145 biomass was similarly estimated using McCauley (1984) and Culver (1985).

146 To estimate functional composition (subsequently the "biotic matrix"), the relative

147 presence (proportion) of each functional trait was calculated as the aggregated biomass of all

148 organisms possessing a specific trait divided by the total community biomass, giving the relative

149 biomass of each functional trait in a sample. For this study, organisms were identified at the

150 species level when possible; however, since many functional traits are conserved within families

151 or orders, it would have been possible to do the same functional analyses using a coarser

152 taxonomical resolution. 
Another objective of this study was to link spatial and temporal changes in plankton

155 functional structure (biotic matrix) to environmental variation, to identify the likely drivers of the observed functional changes. Because plankton may respond to variation in different ecosystem

157 properties, we divided potential drivers into four main categories: morphometric variables (mean 158 depth and lake area), physical variables (mixing depth, secchi depth, water column stability and 159 water column temperature), water quality variables and biotic variables (Table 3). Morphometric 160 variables (Table1) were not influenced by mining activities and thus represented a pure lake identity effect: testing whether lakes with different morphometries had intrinsically different 162 functional composition. Mean depth was calculated using bathymetric surveys and lake area 163 estimated from areal photos or topographic databases using GIS software. Second, lake physics 164 as represented by thermal stratification structure and water column stability can impact plankton 165 community functional composition given that plankton are drifting organisms. Variation in a

166 lake's physical properties may be related to mining activities or to changes occurring at larger 167 scales (e.g. climate warming). Mixing depth and water column stability were estimated from 168 temperature profiles using the R package: Lake Analyzer (Read et al. 2011). Water column 169 temperature was estimated as the mean temperature over the entire water column. The third 170 group of variables encompassed water quality and were likely to be the main effects of mining 171 activities on downstream lakes, via the influence of several chemical variables (see ERM 2014).

172 To characterize water quality, we relied on traditional limnological water quality variables

173 related to important macronutrients (i.e. nitrogen and phosphorus) and $\mathrm{pH}$, turbidity,

174 conductivity, alkalinity, dissolved solids and water hardness as well as potentially toxic

175 compounds (Table S1). Water quality variables were averaged annually, and missing values were 176 replaced by linearly interpolating the preceding and following years. For statistical analyses, we 
177 reduced the number of water quality variables and established the main axes of variation by 178 using the first two principal components (PC1 and PC2) of a Principal Components Analyses 179 (PCA; Figure S1 and Table S1). The main axes of variation in water quality with respect to 180 mining activities were thus represented by an increase in nitrogen (i.e. $\mathrm{NO}_{3}, \mathrm{NO}_{2}$ and $\mathrm{NH}_{4}$ ), 181 water hardness, conductivity, and pH (PC1) with PC2 being related to phosphorus (TP and 182 orthophosphate), metals and turbidity. Finally, because plankton communities do not respond 183 solely to abiotic variables, we also included potential biotic driving variables to account for 184 interaction between the trophic levels. As done for the environmental variables, we used PC1 and 185 PC2 of a "biotic" PCA to capture the main axes of variation in functional trait composition in the 186 other trophic level (phytoplankton for crustacean zooplankton and rotifer and vice-versa, Tables 187 S2, S3, S4 and Figures S2, S3, S4).

191 (Anderson 2001). We first tested the hypothesis that there was no significant interaction between 192 lake Type (monitored vs reference) and Year (Time) on several response variables. If there was a 193 significant Type* Year interaction, it would mean that functional differences between monitored 194 and reference lakes changed through time, indicating an effect of mining activities. The response 195 variable in the PERMANOVA model was the functional composition (biotic matrix). Because 196 we expected the effect of mining activities to be greatest in lakes that were closer to the LLCF,

197 following a significant monitored vs. reference difference, we then compared each group of lakes 198 separately (proximal Leslie and Moose or distal Nema, Slipper and S2) to the reference lakes in a second set of PERMANOVAs to detect whether responses to mining activities were different or 
200 delayed between these. P-values were obtained using 999 permutations under a reduced model 201 constrained within lakes. Our unbalanced statistical design (i.e. five monitored and two reference 202 lakes) could affect rejection rates in the PERMANOVA (Anderson \& Walsh 2013), especially 203 when all lakes are considered. Depending on which group of lakes had the largest variance, the 204 PERMANOVA could either be too liberal or too conservative (Anderson \& Walsh 2013). To 205 compare the variance between reference (2) and monitored (5) lakes we used the betadisper 206 function (vegan $R$ library, Oksanen et al. 2015), and in all cases the variance between monitored 207 lakes was more important than the variance between reference lakes. This indicates that the $p$ 208 values of the PERMANOVA were conservative. In the PERMANOVAs comparing proximal (2) 209 or distal (3) lakes to reference lakes (2), the design was almost balanced, leading to a less biased 210 rejection rate.

213 mining activities was identified), multivariate techniques were used to visualize how the 214 response was structured through time and to identify the drivers of the response in the biotic 215 matrix. We expected the response to mining activities to be structured temporally, such that 216 differences between lakes in the PERMANOVAs would increase with time. We used Principal 217 Response Curves (PRCs) on the biotic matrix to (i) visualize the community functional response 218 through time and (ii) to identify which functional traits responded the strongest. PRCs were 219 conducted only when the effect of mining activities was statistically significant $(\mathrm{p}<0.05)$ in the 220 PERMANOVA. Visualizing temporal trends with multivariate data using standard ordination 221 techniques (e.g. principal component analysis, redundancy analysis) is challenging because in 222 ordination plots, sites will not often be organized in a chronological fashion (van den Brink et al. 
223 2009). PRCs, an extension of redundancy analysis (RDA; using the equation: Response

224 Treatment $\mathrm{x}$ Time + condition(Time)), is a statistical technique that enables the explicit

225 representation of sites in a chronological order and graphically illustrates the temporal deviation

226 of monitored from reference lakes by constraining the ordination using the interaction between

227 treatment Type (monitored versus reference) and Year. In the context of the present study, PRC

228 analysis was used to identify if and when the functional composition of monitored lakes began to

229 deviate from those of reference lakes and to determine whether the timing of the response was

230 related to the distance from the mine (by comparing the proximal vs. distal responses). In PRC

231 diagrams, the effect (displayed on the y-axis) is the first principal component of the treatment

232 effect over time (displayed on the x-axis), which represents the difference of the overall

233 functional response of communities in monitored lakes compared to reference lakes (the zero

234 line). Only the first PRC axis was retained in all cases. All PRCs were performed using the prc

235 function (vegan $R$ library, Oksanen et al. 2015).

PRCs also allowed for the identification of which traits in the biotic matrix were

237 responsible for the differences between monitored and reference lakes and consequently those

238 that responded to mining activities by using PRC “species" weights. As with such scores in other

239 ordination techniques, the relative magnitude of the "species" weights represents how strongly a

240 group (a trait in this case) loads onto the PRC axis, and thus represents the strength of the

241 response by a specific trait (in this case). Also, the sign (+/-) associated to the weight represents

242 whether the response was positive or negative relative to the control (reference) condition. Thus,

243 traits with high absolute weights are the traits that mainly explain the functional difference

244 between monitored and reference lakes. PRC analyses were also conducted on the taxonomic 
245 data and compared to the PRC analyses for functional traits to determine whether similar patterns

246 were observed by the two approaches.

\section{Identifying drivers}

Finally, to confirm that the observed responses were the result of mining activities, we

249 investigated the drivers of the functional changes in the plankton biotic matrix using redundancy

250 analysis (RDA) and variation partitioning. As potential explanatory variables we used water

251 quality parameters (water quality PC1 and PC2) along with the other potential environmental

252 drivers including the morphometric, physical, and biotic variables. We then partitioned the

253 variance explained by the groups of variables (water quality, physical, morphometric and biotic)

254 to better understand the potential sources of variation in plankton functional composition.

255 However, because no variation was independently explained by physical variables in any

256 variation partitioning, we only used water quality, morphometric and biotic variables (see Figure

257 3) to simplify interpretation.

$259 \underline{\text { Results }}$

Effects of mining activities on lake plankton

The effect of mining activities (Year*Type in PERMANOVA) on phytoplankton functional composition was significant for proximal and distal lakes when compared to reference lakes

263 (Table 4; main effects are in Table S5). For rotifers the effect of mining activities on functional 264 composition was significant (Table 4). Finally, for crustacean zooplankton, the effect of mining 265 activities on functional composition was significant both in proximal and distal lakes compared 266 to reference lakes (Table 4). 
267

268

269

270

271

272

273

274

275

276

277

278

279

280

281

282

283

284

285

286

287

288

289

Responses of plankton communities to mining through time

The phytoplankton functional composition response curves (PRC) showed a clear

temporal divergence of monitored lakes from reference lakes (horizontal vs. other lines in Figure

3a). Moreover, the timing of the functional composition response was proportional to the

distance from the mine: the closest lake (Leslie) responded first, followed by Moose, and Nema.

Slipper responded after 2005, while S2 only started to respond in 2010. Although differences

between monitored and reference lakes were significant through the whole sampling period, the

divergence in functional composition between these lakes clearly increased with time.

Furthermore, following the initial responses in Leslie, Moose, and Nema (lakes proximal to the

LLCF), the functional divergence of phytoplankton appears to have stabilized around the same

level of difference from reference, despite variation in the downstream distance from the LLCF.

Monitored lakes had greater biomass of edible and non-motile phytoplankton, and with high

silica demand (Figure 3a), with decreases over time in mixotrophic, flagellated and colonial

phytoplankton traits. The temporal pattern displayed by phytoplankton taxonomic composition

(Figure S5) was also almost identical to functional composition, with Cyclotella, Cryptomonas and Dinobryon responding the most.

For rotifers, prior to 2009, the first PRC axis of functional composition showed mainly differences between distal lake S2 and the other lakes indicating lake-specific differences (Figure 3b). It was only after 2009 that a clear divergence of proximal lakes from reference and distal lakes occurred (Figure 3b). The functional composition divergence occurred later for rotifers than for phytoplankton, and does not have appear to have stabilized. The observed functional response in proximal lakes (Figure 3b) was a shift from conical species (predominantly of the genus Kellicotia) to parallelepiped species (predominantly of the genus Keratella, see Figure 
290 S6). In the rotifer PRC, Nema and Slipper diverged from reference lakes in 2012, but in a

291 different direction than Leslie and Moose (Figure 3b and Figure S6). This divergence was not the

292 result of functional compositional shifts in Nema and Slipper but was rather the result of a

293 change in reference lake rotifer composition (i.e. the zero line). In S2 there was important annual

294 variation in the proportion of Asplanchna, a very large rotifer, while proximal lakes shifted from

295 being dominated by Kellicottia, a species with long protective spines, to Keratella a species that

296 has shorter spines.

For crustacean zooplankton, despite a significant effect of Year*Type detected in the PERMANOVA analyses, there was no directional temporal pattern in the differences between monitored and reference lakes, and no clear functional shift through time (Figure 3c). Together, these results suggest that there was a small effect of mining activities on crustacean zooplankton composition, but that the response was year-specific. In general, monitored lakes had greater

302 abundances of herbivores, fast swimming (RSS6) stationary suspension feeders, characterized taxonomically by species within the Calanoida order, with lower relative dominance of slow

304 swimming taxa and immature stages. Temporal patterns in crustacean zooplankton taxonomic composition were similar to the trends in functional composition, again, with no clear temporal 306 pattern (Figure S7). Also, before mining activities started (in 1996 and 1997) there was a 307 compositional shift in Moose and Nema (see figure 3c and figure S7). This shift was mainly explained by a decrease in the relative abundance of Holopedium in Nema and Moose. 
313 strongly on this axis were the same as those identified in the PRC (Figure 3a). Water quality PC1

314 (WQ PC1) loaded strongly on RDA axis 1, along with PC1 of crustacean zooplankton (Crust

315 PC1), which also loaded positively on the first axis. On the other hand, lake morphometric

316 variables (Mean $\mathrm{Z}$ and $\log$.Lake Area) loaded negatively on the first axis, while physical

317 variables (WC stability) loaded positively. Most of the explained variation in the phytoplankton

318 functional RDA was independently explained by water quality $(23 \%, \mathrm{p}<0.0001$; Table 5$)$. All the

319 variation explained by morphometry was shared with water quality, biotic variables or both. A

320 highly significant $(p=0.001$ ) $6 \%$ fraction of the variation was also independently explained by

321 biotic variables.

For rotifer functional composition, the first axis explained $33 \%$ and the second $13 \%$ of

323 the variation in the RDA (Figure 5). Morphometry (Mean Z and log.Lake Area) and water

324 quality PC1 (WQ PC1) had strong loadings on the first two axes, while crustacean PC2 (Crust

325 PC2) loaded on the first axis and phytoplankton PC1 (Phyto PC1) on the second. The importance

326 of lake area was consistent with the observation that S2, a large lake, was functionally different,

327 dominated by ellipsoid species. Parallelepiped rotifers were associated to changes in water

328 quality variables resulting from mining activities (WC PC1). Variation partitioning demonstrated

329 that lake morphometry independently explained a large and significant $(16 \%, \mathrm{p}<0.0001$; Table 5)

330 amount of the variation in the RDA. Water quality $(17 \%, \mathrm{p}<0.0001)$ and biotic variables $(6 \%$,

$331 \mathrm{p}=0.001$ ), also significantly independently explained variation in rotifer functional composition.

The first axis of the crustacean zooplankton functional composition RDA explained 23\%

333 of the total variation and the second $9 \%$ of the constrained variation (Figure 6 ). On the first axis, 334 water quality PC1 (WQ PC1), morphometric (mean Z), physical (Secchi Z and Thermocline Z), 335 and biotic variables (Phyto PC1 and Phyto PC2) had strong loadings. As observed for 
336 phytoplankton and rotifers, the functional traits that loaded strongly on the first axis were the 337 same that responded in the PRC (i.e. Stat. susp., RSS 6, RSS 0 and Immature). Along the 338 weaker second axis, rotifers and crustacean traits of carnivory and raptorial feeding loaded. One 339 important difference in the variation partitioning (Table 5), was that water quality variables 340 independently explained only $2 \%$ of the variation $(p=0.01)$, while biotic and morphometric 341 variables independently explained $8 \%$ and $10 \%$ of the variation $(\mathrm{p}<0.0001$ for both). The 342 variation independently explained by water quality was low, but could be more important 343 because of the shared variation with morphometry and biotic variables.

$\underline{\text { Discussion }}$

The aggregate effects of diamond mining activities on the functional composition of the

347 plankton communities in the focal northern Canadian watershed were significant across community types. The response to mining activity of phytoplankton and rotifer communities had

349 a strong temporal structure and was sequential: functional changes occurred first in proximal 350 lakes, followed by distal lakes. The functional composition response in phytoplankton was 351 strongly linked to water quality and appeared many years before that of the rotifers, suggesting a 352 bottom-up progression of effects. The long-time-lag between the responses of the different 353 trophic levels, occurring over several years was surprising considering that plankton organisms

354 have very short generation times and can thus respond rapidly to a changing environment 355 (McCormick \& Cairns 1994; Stemberger \& Lazorchak 1994); it is possible that longer 356 development times combined with shorter growing seasons in more northerly environments 357 would delay the response. A community response in the crustacean zooplankton was less 358 obvious, and although there was a significant effect on functional composition in the 
359 PERMANOVA, no directional temporal patterns in functional change in the crustacean

360 zooplankton community were observed in the PRCs. The lack of a temporal directional trend

361 suggests that the observed differences between monitored and reference lakes were year-specific

362 rather than related to mining activities.

In the phytoplankton, although they responded strongly, traits related to edibility

364 (edibility, motility, free-living) were probably not the only ones under selection, as the

365 phytoplankton functional composition in monitored lakes shifted toward small centric diatoms, a

366 functional group that is usually favored when unproductive lakes are enriched with nitrogen (see

367 Saros and Anderson 2015 for a review). Although we cannot directly attribute the response of

368 phytoplankton to $\mathrm{N}$-enrichment, it is the most plausible explanation according to recent studies

369 that have shown a strong response of small centric diatoms to this factor (Winder and Hunter

370 2008, Saros et al. 2012, 2014). On the other hand, the effect of lake thermal structure was not

371 significant, although it has also been identified as a driver of small centric diatom abundance in

372 northern lakes (see Rühland et al. 2015 for a review). The strong response we observed in traits

373 related to phytoplankton edibility should favor a bottom-up trophic response of zooplankton.

Rotifer communities also shifted toward smaller species (mainly Keratella), and these

375 shifts were related to nutrient (mainly N) enrichment. In the Great Lakes, a similar shift from

376 Kellicottia dominance under oligotrophic conditions, to Keratella under eutrophic conditions has

377 also been observed (Barbiero \& Warren 2011). The response of rotifer functional composition to

378 changes in phytoplankton and crustacean zooplankton functional composition also validates the

379 presence of a trophic response. However, the restricted amount of functional knowledge on

380 rotifer species in the literature limits the ecological interpretations we can draw for this group. 
Given the shift toward more edible and accessible (non-colonial, non-motile)

382

383

384

385

386

387

388

389

390

391

392

393

394

395

396

397

398

399

400

401

402

403

phytoplankton biomass, we would expect highly competitive crustacean zooplankton (i.e. large, filter-feeding cladocerans) to dominate (Lampert \& Schober 1980). Furthermore, diatoms are of high nutritional quality (Brett \& Müller-Navarra 1997), especially for herbivorous filter-feeders (Richman \& Dodson 1983). However, we did not observe a concomitant shift toward herbivorous filter-feeding cladocerans, but instead an increased dominance by the functional traits reflecting the calanoid copepods; the group that had already dominated prior to mining onset. One potential explanation for the absence of a shift toward filter-feeders could be that while food quantity and quality increased, phytoplankton concentrations (average of 742 cells/ml, Figure 7) were almost always under or close to the lowest concentration limit for cladocerans established at 1000 cells/ml (see Lampert and Schober 1980), except in Nema where the average was 2732 cell/ml (Figure 7). Consequently, calanoids would have maintained a competitive edge with their lower food concentration limit (see McNaught 1975). Because cyclopoid copepods are one of the main predators of planktonic rotifers (Williamson 1983), we also expected a response of crustacean zooplankton to functional changes in the rotifer community, especially if a shift in potential edibility was observed. Although, both Kellicottia and Keratella are common prey for many copepod species (Williamson 1983), and the fact that we observe a negative relation between rotifers and raptorial and carnivorous zooplankton in the crustacean zooplankton RDA (Figure 6 Axis 2), the functional shift in rotifers with mining, did not affect overall community edibility in a way that influenced the primary crustacean zooplankton response (Figure 6 Axis 1). In this RDA and in the variation partitioning, changes in water quality resulting from mining (WQ PC1) had small but significant effects on crustacean zooplankton functional composition, indicating only minor effects of mining activities on 
crustacean zooplankton. Given that during the implementation of mining activities there were non-directional changes in crustacean zooplankton functional composition, there is little evidence to indicate that crustacean zooplankton community composition in the studied lakes are related to the mine. Instead, the original community composition appears to have been reinforced in lakes impacted by mining activity. Thus, with respect to bottom-up effects propagating through the food web, mining effects on fish are likely to be minor as well. However, a full assessment of the fish communities would also need to be done to determine this more definitively, as there could be direct effects on fish that are beyond the influence of the food web.

By using a functional traits approach, we successfully synthesized shifts that took place at the taxonomic level: taxonomic composition principle response curves were highly similar to the response curves of functional composition for all zooplankton and phytoplankton. Overall, the functional approach offers promise to lake management in that it can reflect taxonomic shifts in plankton communities in response to environmental change.

Changes in water quality as a result of diamond mining activities have caused a functional shift in phytoplankton and rotifer communities in the lakes downstream of the mine. However, there are strong indications that after almost 20 years of activity, the impact of mining has been restricted to the base of the food web and that the functional structure of plankton communities is stabilizing over time. The weaker directional shift in crustacean zooplankton suggests minimal bottom-up effects are also likely for the fish communities in these lakes. For the mining industry, monitoring functional shifts in plankton traits composition at best, will enable an excellent and potentially broadened understanding of the impacts of mining activities on aquatic communities. Classifying individuals more broadly into coarse taxonomic groups (i.e. genus or family rather than species) is usually sufficient to allow the implementation of a 
427 functional approach. Thus, this type of monitoring involves overall a smaller allocation of

428 resources, expertise and time to classify taxa into functional groups. Our results show that it is

429 likely to be a productive approach to assessing responses by aquatic communities to industrial

430 perturbation and aid in environmental monitoring of lakes more generally.

\section{Acknowledgments}

432 Thanks to Erin Forster, Amy Elliott, Mark Nelson, Tom Jeffery, Laurie Ainsworth, Benjamin

433 Beall, April Hayward, and Claudine Lee for help with the data collection, study design, and

434 manuscript review. This research was funded by an Engage Grant (EGP 475781-14) from the

435 Natural Sciences and Engineering Research Council of Canada (NSERC) to BEB. As part of its

436 partnership in the Engage Grant, DDEC provided in kind contributions. ERM Consultants

437 Canada Inc. provided logistical and technical support. Dominion Diamond Corporation (DDEC)

438 collected the data and provided access to the databases. 


\section{$\underline{\text { Literature cited }}$}

Anderson, M.J. (2001) A new method for non-parametric multivariate analysis of variance. Austral Ecology, 26, 32-46.

Anderson, M.J. \& Walsh, D.C.I. (2013) PERMANOVA, ANOSIM, and the Mantel test in the face of heterogeneous dispersions: What null hypothesis are you testing? Ecological Monographs, 83, 557-574.

Barbiero, R.P. \& Warren, G.J. (2011) Rotifer communities in the Laurentian Great Lakes, 19832006 and factors affecting their composition. Journal of Great Lakes Research, 37, 528540.

Barnett, A.J. \& Beisner, B.E. (2007) Zooplankton biodiversity and lake trophic state: explanations invoking resource abundance and distribution. Ecology, 88, 1675-86.

Barnett, A.J., Finlay, K. \& Beisner, B.E. (2007) Functional diversity of crustacean zooplankton communities: towards a trait-based classification. Freshwater Biology, 52, 796-813.

Brett, M.T. \& Müller-Navarra, D.C. (1997) The role of highly unsaturated fatty acids in aquatic foodweb processes. Freshwater Biology, 38, 483-499.

van den Brink, P.J., den Besten, P.J., bij de Vaate, A. \& ter Braak, C.J.F. (2009) Principal response curves technique for the analysis of multivariate biomonitoring time series. Environmental Monitoring and Assessment, 152, 271-281.

Carvalho, L., Poikane, S., Solheim, A.L., Phillips, G., Borics, G., Catalan, J., De Hoyos, C., Drakare, S., Dudley, B.J., Jarvinen, M., Laplace-Treyture, C., Maileht, K., McDonald, C., Mischke, U., Moe, J., Morabito, G., Noges, P., Noges, T., Ott, I., Pasztaleniec, A., 
Skjelbred, B. \& Thackeray, S.J. (2013) Strength and uncertainty of phytoplankton metrics for assessing eutrophication impacts in lakes. Hydrobiologia, 704, 127-140.

Culver, D.A., Boucherle, M.M., Bean, D.J. \& Fletcher, J.W. (1985) Biomass of Freshwater Crustacean Zooplankton from Length-Weight Regressions. Canadian Journal of Fisheries and Aquatic Sciences, 42, 1380-1390.

Downing, J. a \& McCauley, E. (1992) The nitrogen:phosphorus relationship in lakes. Limonology And Oceanography, 37, 936-945.

ERM (2014) Ekati Diamond Mine: 2014 Aquatic Effects Monitoring Program Part 2 - Data Report. Prepared for Dominion Diamond Ekati Corporation by ERM Consultants Canada Ltd.: Yellowknife, Northwest Territories.

Gu, B., Schelske, C.L. \& Hoyer, M. V (1996) Stable isotopes of carbon and nitrogen as indicators of diet and trophic structure of the fish community in a shallow hypereutrophic lake. Journal of Fish Biology, 49, 1233-1243.

Gu, B.H., Schell, D.M. \& Alexander, V. (1994) Stable carbon and nitrogen isotopic analysis of the plankton food web in a subarctic lake. Canadian Journal of Fisheries and Aquatic Sciences, 51, 1338-1344.

Hillebrand, H., Durselen, C.-D., Kirschtel, D., Pollingher, U. \& Zohary, T. (1999) Biovolume calculation for pelagic and benthic microalgae. Journal of Phycology, 35, 403-424.

Hooper, D.U., Chapin III, F.S. \& Ewel, J.J. (2005) Effects of biodiversity on ecosystem functioning: a consensus of current knowledge. Ecological Monographs, 75, 3-35.

Jeppesen, E., Jensen, J.P., Sondergaard, M., Lauridsen, T. \& Landkildehus, F. (2000a) Trophic 
structure, species richness and biodiversity in Danish lakes: Changes along a phosphorus gradient. Freshwater Biology, 45, 201-218.

Jeppesen, E., Lauridsen, T.L., Mitchell, S.F., Christoffersen, K. \& Burns, C.W. (2000b) Trophic structure in the pelagial of 25 shallow New Zealand lakes: changes along nutrient and fish gradients. Jouranl of Plankton Research, 22, 951-968.

Khalifa, N., El-damhogy, K.A., Fishar, M.R., Nasef, A.M. \& Hegab, M.H. (2015) Using zooplankton in some environmental biotic indices to assess water quality of Lake Nasser, Egypt. International Journal of Fisheries and Aquatic Studies, 2, 281-289.

Kling, G.W., Fry, B. \& O’Brien, J.W. (1992) Stable isotopes and planktonic trophic structure in Arctic lakes. Ecology, 73, 561-566.

Lampert, W. \& Schober, U. (1980) The importance of “threshold"food concentrations. Evolution and ecology of zooplankton communities. University Press of New England, 264-267.

Longhi, M.L. \& Beisner, B.E. (2010) Patterns in taxonomic and functional diversity of lake phytoplankton. Freshwater Biology, 55, 1349-1366.

McCauley, E. (1984) The estimation of the abundance and biomass of zooplankton in samples. $A$ manual on methods for the assessment of secondary productivity in fresh waters. Blackwell Scientific, Oxford, UK, 228-265.

McCormick, P. V. \& Cairns, J. (1994) Algae as indicators of environmental change. Journal of Applied Phycology, 6, 509-526.

McNaught, D.C. (1975) A hypothesis to explain the succession from calanoids to cladocerans during eutrophication. Verhandlungen, Internationale Vereinigung fuer Theoretische und 
Angewandte Limnologie, 19.

Monchamp, M.E., Pick, F.R., Beisner, B.E. \& Maranger, R. (2014) Nitrogen forms influence microcystin concentration and composition via changes in cyanobacterial community structure. PLoS ONE, 9.

Oksanen, J., Blanchet, F.G., Kindt, R., Legendre, P., Minchin, P.R., O’Hara, R.B., Simpson, G.L., Solymos, P., Henry, M., Stevens, H. \& Wagner, H. (2015) vegan: Community Ecology Package. R package version 2.3-0.

Orihel, D.M., Bird, D.F., Brylinsky, M., Chen, H., Donald, D.B., Huang, D.Y., Giani, A., Kinniburgh, D., Kling, H., Kotak, B.G., Leavitt, P.R., Nielsen, C.C., Reedyk, S., Rooney, R.C., Watson, S.B., Zurawell, R.W., Vinebrooke, R.D. \& Smith, R.E.H. (2012) High microcystin concentrations occur only at low nitrogen-to-phosphorus ratios in nutrient-rich Canadian lakes. Canadian Journal of Fisheries and Aquatic Sciences, 69, 1457-1462.

Paerl, H.W. \& Otten, T.G. (2013) Harmful Cyanobacterial Blooms: Causes, Consequences, and Controls. Microbial Ecology, 65, 995-1010.

Read, J.S., Hamilton, D.P., Jones, I.D., Muraoka, K., Winslow, L. a., Kroiss, R., Wu, C.H. \& Gaiser, E. (2011) Derivation of lake mixing and stratification indices from high-resolution lake buoy data. Environmental Modelling \& Software, 26, 1325-1336.

Rescan (2012) EKATI Diamond Mine: 2012 Aquatic Effects Monitoring Program Reevaluation. Prepared for BHP Billiton Canada Inc.

Richman, S. \& Dodson, S.I. (1983) The Effect of Food Quality on Feeding and Respiration by Daphnia and Diaptomus. Limnology and Oceanography, 28, 948-956. 
Rühland, K.M., Paterson, A.M. \& Smol, J.P. (2015) Lake diatom responses to warming: reviewing the evidence. Journal of Paleolimnology.

Saros, J.E. \& Anderson, N.J. (2015) The ecology of the planktonic diatom Cyclotella and its implications for global environmental change studies. Biological Reviews, 90, 522-541.

Saros, J.E., Stone, J.R., Pederson, G.T., Slemmons, K.E.H., Spanbauer, T., Schliep, A., Cahl, D., Williamson, C.E. \& Engstrom, D.R. (2012) Climate-induced changes in lake ecosystem structure inferred from coupled neo- and paleoecological approaches. Ecology, 93, 21552164.

Saros, J.E., Strock, K.E., McCue, J., Hogan, E. \& Anderson, N.J. (2014) Response of Cyclotella species to nutrients and incubation depth in Arctic lakes. Journal of Plankton Research, 36, $450-460$.

Stemberger, R.S. \& Lazorchak, J.M. (1994) Zooplankton Assemblage Responses to Disturbance Gradients. Canadian Journal of Fisheries and Aquatic Sciences, 51, 2435-2447.

The Conference Board of Canada (2013) The Future of Mining in Canada's North,.

Whitton, B.A., Rott, E. \& Friedrich, G. (1991) Use of algae for monitoring rivers. Journal of Applied Phycology, 3, 287.

Williamson, C.E. (1983) Invertebrate predation on planktonic rotifers. Biology of Rotifers, pp. 385-396. Springer.

Winder, M. \& Hunter, D. a. (2008) Temporal organization of phytoplankton communities linked to physical forcing. Oecologia, 156, 179-192. 
Table 1: Geographic coordinates of the study lakes, and their morphometric and physical characteristics. Physical characteristics were averaged over the 19-year sampling period and the standard error is reported in parentheses.

\begin{tabular}{cccccccccc} 
& Lake & Lat. & Long. & Area $(\mathrm{m} 2)$ & $Z_{\text {mean }}(\mathrm{m})$ & $Z_{\text {mixed }}(\mathrm{m})$ & $Z_{\text {secchi }}(\mathrm{m})$ & Temp. (oC) & Stability \\
\hline \multirow{2}{*}{ Proximal } & Leslie(Le) & 64.68 & -110.67 & $6.2 \mathrm{E}+05$ & 5.8 & $9.4(0.7)$ & $6.3(0.5)$ & $13.1(0.5)$ & $69(16)$ \\
& Moose(Mo) & 64.68 & -110.65 & $4.4 \mathrm{E}+02$ & 1.5 & $6.9(0.4)$ & $6(0.4)$ & $12.7(0.4)$ & $61(12)$ \\
\hline \multirow{3}{*}{ Distal } & Nema(Ne) & 64.68 & -110.72 & $7.8 \mathrm{E}+05$ & 1.9 & $6.8(0.5)$ & $4(0.2)$ & $14.1(0.5)$ & $18(6.2)$ \\
& Slipper(Si) & 64.61 & -110.85 & $1.9 \mathrm{E}+06$ & 3.2 & $10.5(0.5)$ & $4.1(0.15)$ & $12.5(0.4)$ & $80(14)$ \\
& $\mathrm{S} 2$ & 64.61 & -110.84 & $1.4 \mathrm{E}+08$ & 11.5 & $4.5(0.4)$ & $5.5(0.2)$ & $12.2(0.4)$ & $132(102)$ \\
\hline \multirow{2}{*}{ Reference } & Nanuq(Na) & 64.92 & -110.28 & $3.1 \mathrm{E}+07$ & 28.5 & $15.9(1.1)$ & $8.5(0.5)$ & $10.7(0.25)$ & $65(8)$ \\
& Counts(Co) & 64.65 & -110.29 & $1.2 \mathrm{E}+06$ & 8.9 & $9.8(0.5)$ & $5.4(0.2)$ & $14(0.4)$ & $23(8)$ \\
\hline
\end{tabular}


Table2: Phytoplankton, rotifer and crustacean zooplankton functional traits and levels

\begin{tabular}{|c|c|c|c|}
\hline & Category & Traits & Values \\
\hline \multirow{13}{*}{ 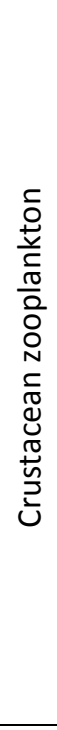 } & \multirow{12}{*}{ Resource acquisition } & \multirow{6}{*}{ Trophic position } & Carnivore \\
\hline & & & Omnivore-Carnivore \\
\hline & & & Omnivore \\
\hline & & & Omnivore-Herbivore \\
\hline & & & Herbivore \\
\hline & & & Immature \\
\hline & & \multirow{6}{*}{ Feeding type } & $\mathrm{B}$ (Bosmina)-filtration \\
\hline & & & C(Chydorus)-filtration \\
\hline & & & $\mathrm{D}$ (Daphnia)-filtration \\
\hline & & & S(Sidae)-filtration \\
\hline & & & Stationary Suspension \\
\hline & & & Raptorial \\
\hline & Predation avoidance & $\begin{array}{c}\text { Relative swimming } \\
\text { speed (RSS) }\end{array}$ & 0 (slow)-6(fast) \\
\hline \multirow{6}{*}{ 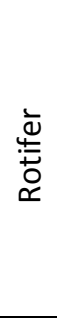 } & \multirow{6}{*}{ Predation avoidance } & & Cone \\
\hline & & Shape & Cylinder \\
\hline & & & Ellipsoid \\
\hline & & & Parallelepiped \\
\hline & & Spines & yes/no \\
\hline & & Colonial & yes/no \\
\hline \multirow{12}{*}{ 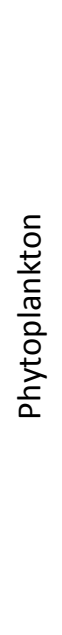 } & \multirow{7}{*}{ Resource acquisition } & Nitrogen Fixation & yes/no \\
\hline & & Si requirement & yes/no \\
\hline & & Mixotroph & yes/no \\
\hline & & \multirow{4}{*}{ Pigments } & Green \\
\hline & & & Blue \\
\hline & & & Brown \\
\hline & & & Mixed \\
\hline & \multirow{5}{*}{ Predation avoidance } & & None \\
\hline & & Motility & Flagellated \\
\hline & & & Vacuole \\
\hline & & Edible & yes/no \\
\hline & & Colonial & yes/no \\
\hline
\end{tabular}


Table 3: Variables used in the RDA as response and explanatory variables. "Other communities" refers to the principal components (PC1 and PC2) associated with PCAs done on all taxa excluding the focal community in each case (Tables S2, S3, S4 and Figure S2, S3 and $\mathrm{S} 4)$. $\mathrm{Z}$ refers to depths of: mean lake (Mean $Z)$, mixed layer depth $\left(Z_{\text {mixed }}\right)$ and secchi depth $\left(Z_{\text {secchi }}\right)$.

\begin{tabular}{|c|c|c|c|c|}
\hline Composition & Morphometry & Physical & $\begin{array}{c}\text { Water } \\
\text { Quality }\end{array}$ & Biotic \\
\hline Response variables & & \multicolumn{4}{|c|}{ Explanatory variables } \\
\hline $\begin{array}{c}\text { Community } \\
\text { functional } \\
\text { composition }\end{array}$ & Lake Area $(\mathrm{m})$ & $\begin{array}{c}\mathrm{Z}_{\text {secchi }}(\mathrm{m}) \\
\text { Stability }(\mathrm{RTR})\end{array}$ & PC2 & $\begin{array}{c}\text { PC1 \& PC2 Other } \\
\text { communities }\end{array}$ \\
& & Temperature $\left({ }^{\circ} \mathrm{C}\right)$ & & $\begin{array}{c}\text { Total biomass of } \\
\text { other communities }\end{array}$ \\
\hline
\end{tabular}


Table 4 Simplified PERMANOVA table, the interaction of Year*Type test for the significance of mining activities on functional composition. Based on 999 permutations. See Table S-1 for the full PERMANOVA table.

\begin{tabular}{c|ccc|ccc|ccc}
\hline & \multicolumn{3}{|c|}{ Overall } & \multicolumn{3}{c|}{ Proximal } & \multicolumn{3}{c}{ Distal } \\
& SS & $\mathrm{F}$ & $\mathrm{p}$ & $\mathrm{SS}$ & $\mathrm{F}$ & $\mathrm{p}$ & $\mathrm{SS}$ & $\mathrm{F}$ & $\mathrm{p}$ \\
\hline Phytoplankton & 1.1 & 4.2 & 0.005 & 2.2 & 5.4 & 0.007 & 1.5 & 3.8 & 0.04 \\
Rotifer & 1.2 & 3.4 & 0.045 & 2 & 16.8 & 0.001 & 1 & 3.8 & 0.07 \\
Crustacean & 2.8 & 3.5 & 0.002 & 3.9 & 10.7 & 0.003 & 2.6 & 3.8 & 0.009 \\
\hline
\end{tabular}


Table 5: Adjusted $\mathrm{R}^{2}$ values from the variance partitioning on functional composition by plankton group shown as percentages for each fraction, as defined in Figure 2. Only the W, B and M fractions were statistically testable with significance ( $\mathrm{p}$-values) corresponding to $* \mathrm{p}<.05, * * \mathrm{p}<0.001$ and $* * * \mathrm{p}<0.0001$.

\begin{tabular}{|l|c|c|c|c|c|c|c|}
\hline & $\mathrm{W}$ & $\mathrm{B}$ & $\mathrm{M}$ & $\mathrm{W}+\mathrm{M}$ & $\mathrm{W}+\mathrm{B}$ & $\mathrm{B}+\mathrm{M}$ & $\mathrm{W}+\mathrm{B}+\mathrm{M}$ \\
\hline Phytoplankton & $0.23^{* * *}$ & $0.06^{* *}$ & 0 & 0.03 & 0.5 & 0.03 & 0.08 \\
\hline Rotifer & $0.17 * * *$ & $0.06 * *$ & $0.16^{* * *}$ & 0 & 0.03 & 0.04 & 0 \\
\hline Crustacean zooplankton & $0.02 *$ & $0.08^{* * *}$ & $0.1 * * *$ & 0.02 & 0.03 & 0.02 & 0.05 \\
\hline
\end{tabular}




\section{Figure captions}

Figure 1: Map of the lakes showing the LLCF proximal lakes: Leslie (Le) and Moose (Mo), and the distal lakes: Nema (Ne), Slipper (S1) and station 2 of Lake de Gras (S2) in the Koala Watershed. Nanuq $(\mathrm{Na})$ and Counts $(\mathrm{Co})$ from a nearby watershed were reference lakes.

Figure 2: Venn diagram showing the structure of the variation partitioning analyses. Results for each fraction are shown in Table 5.

Figure 3: Principal Response Curves (PRC) for functional composition of: (a) phytoplankton, (b) rotifers, and (c) crustacean zooplankton in the monitored lakes (Leslie, Moose, Nema, Slipper and S2) vs. reference (Nanuq and Counts; the 0 line) lakes. The red lines indicate the year mining activities began (1998). Weights show the degree to which functional traits responded to mining activities. For clarity, only traits with an absolute weight $>0.5$ are shown.

Figure 4: Ordination diagram of the phytoplankton functional composition RDA. Functional traits (response variables) are represented by crosses, and environmental variables (explanatory variables) by arrows. On each axis, constrained (const.) and total explained variation is reported. The unlabelled arrows correspond to the following variables starting in quadrant 1 (closest to $12: 00$ on a clock) and moving in a clockwise direction: WC temperature, Biomass crustacean, Rotifer PC2, Rotifer PC1, Thermocline Z, Biomass rotifer and Crustacean PC2.

Figure 5: Ordination diagram of the rotifer functional composition RDA. Functional traits (response variables) are represented by crosses and environmental variables (explanatory variables) by arrows. On each axis, constrained (const.) and total explained variation is 
reported. The unlabelled arrows correspond to the following variables starting in quadrant 1(closest to 12:00 on a clock) and moving in a clockwise direction: WQ stability, Secchi depth, Biomass phytoplankton, Crustacean PC1. Phytoplankton biomass, phytoplankton PC2, WC temperature and WQ PC2.

Figure 6: Ordination diagram of the crustacean zooplankton functional composition RDA. Functional traits (response variables) are represented by crosses, and environmental variables (explanatory variables) are represented by arrows. On each axis, constrained (const.) and total explained variation is reported. The unlabelled arrows correspond to the following variables starting in quadrant 1 (closest to 12:00 on a clock) and moving in a clockwise direction: WQ stability and Biomass phytoplankton.

Figure 7: Boxplot of median total phytoplankton abundance in each lake. The grey horizontal line represents the Daphnia lower food concentration limit according to Lampert (1980). 


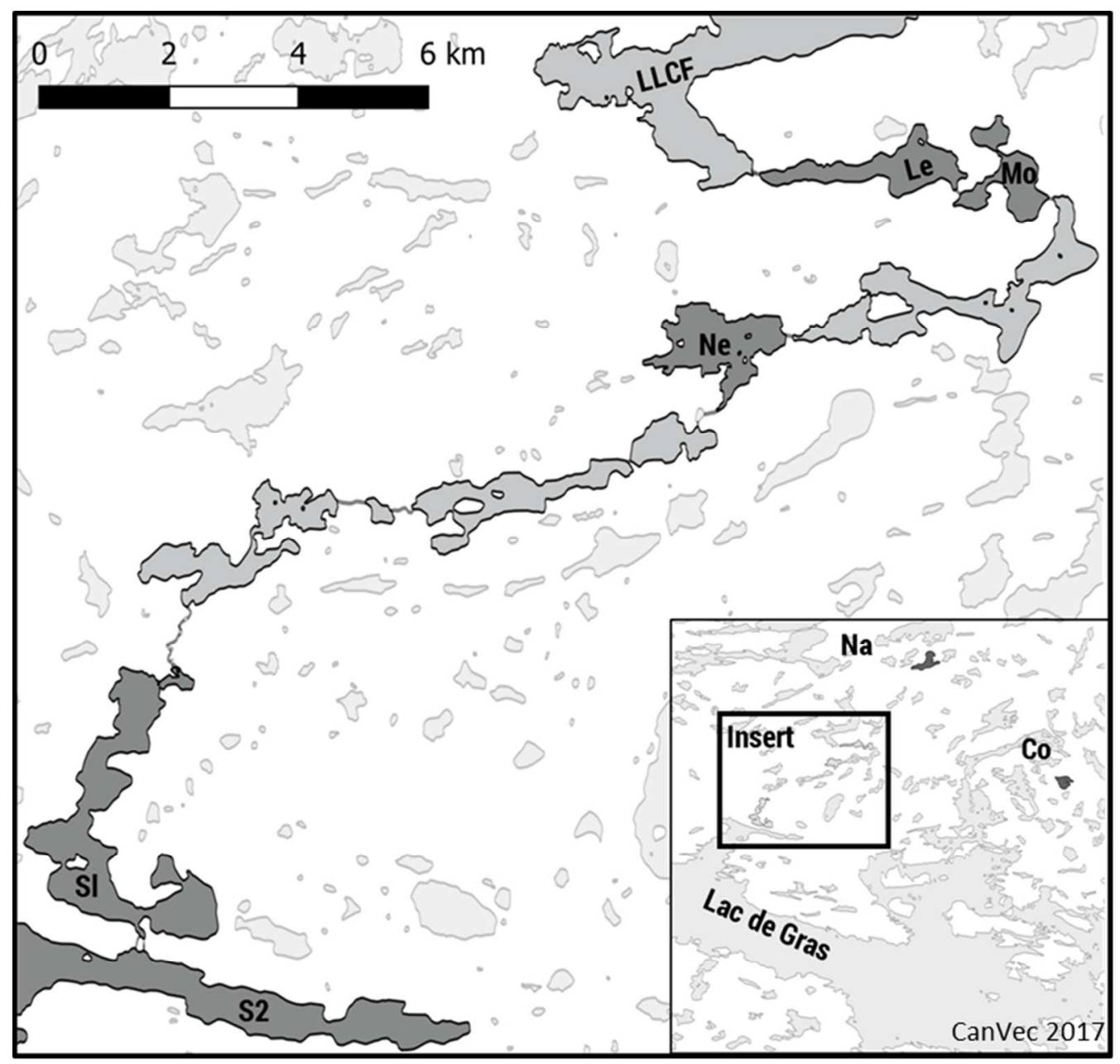

Figure 1 


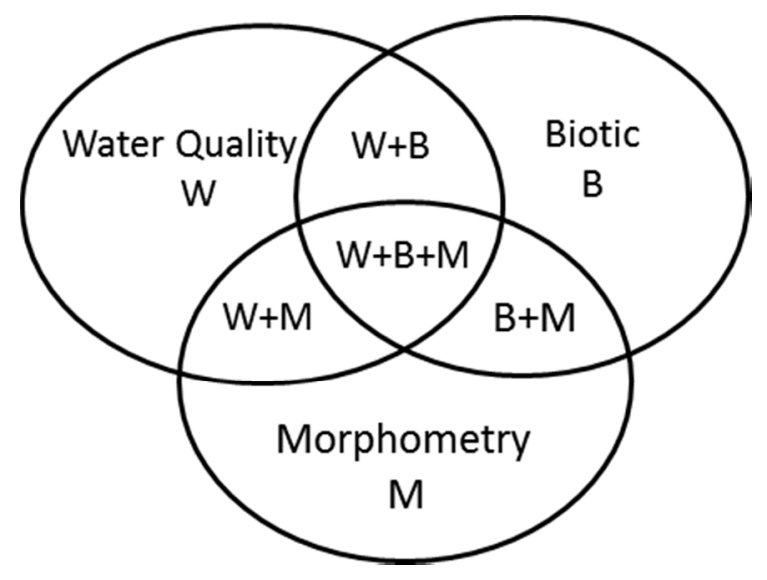

Figure 2 

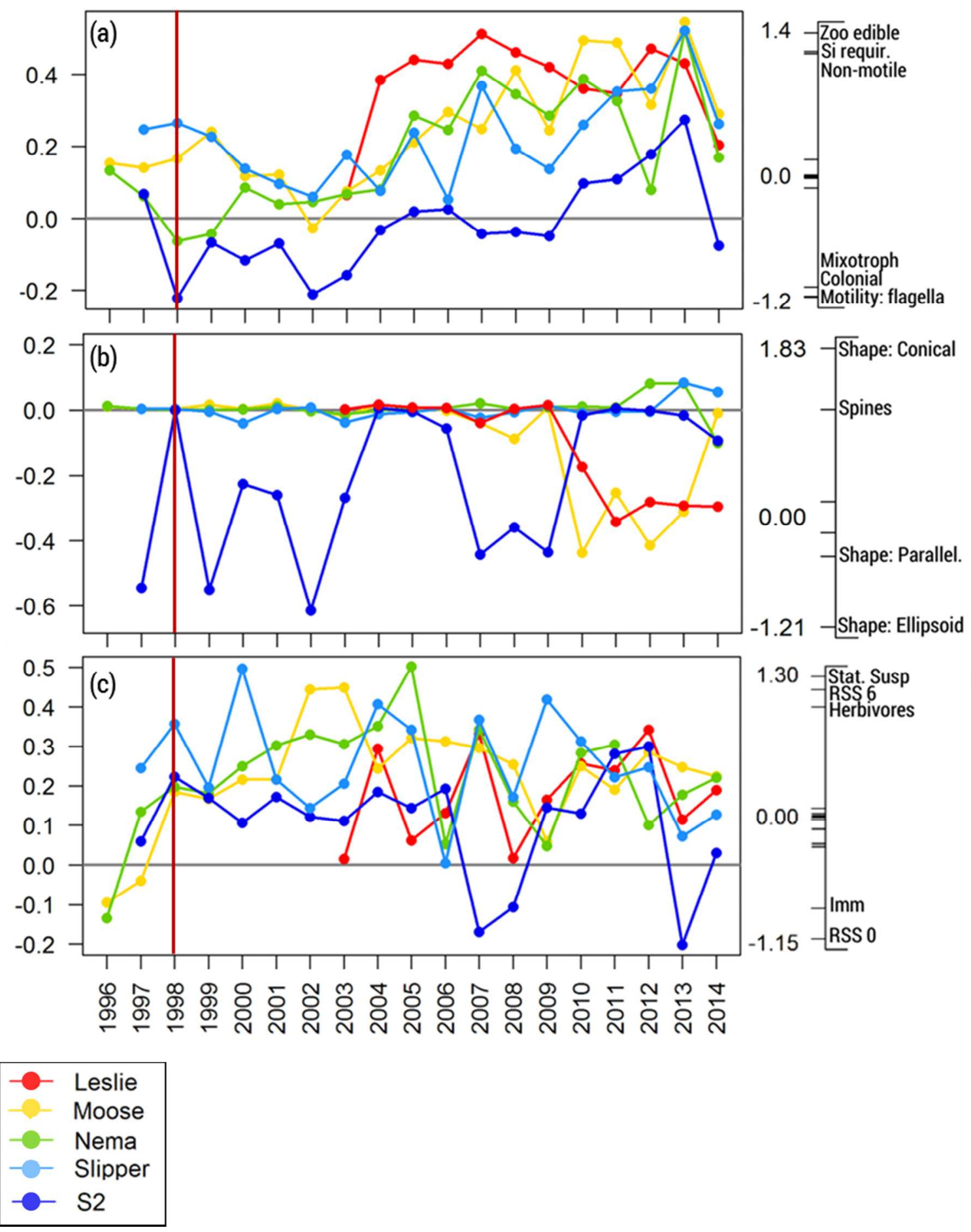

Figure 3 


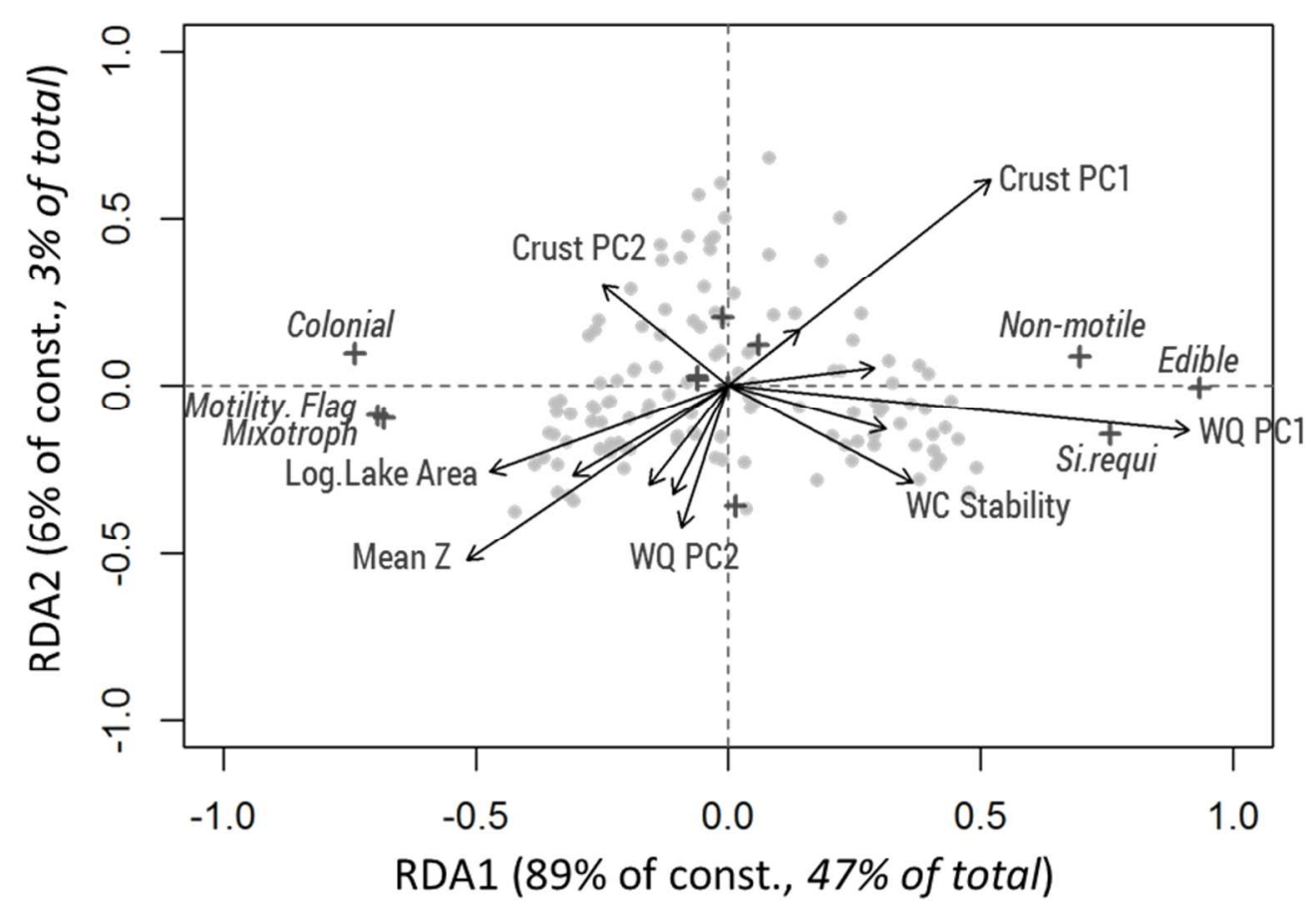

Figure 4 


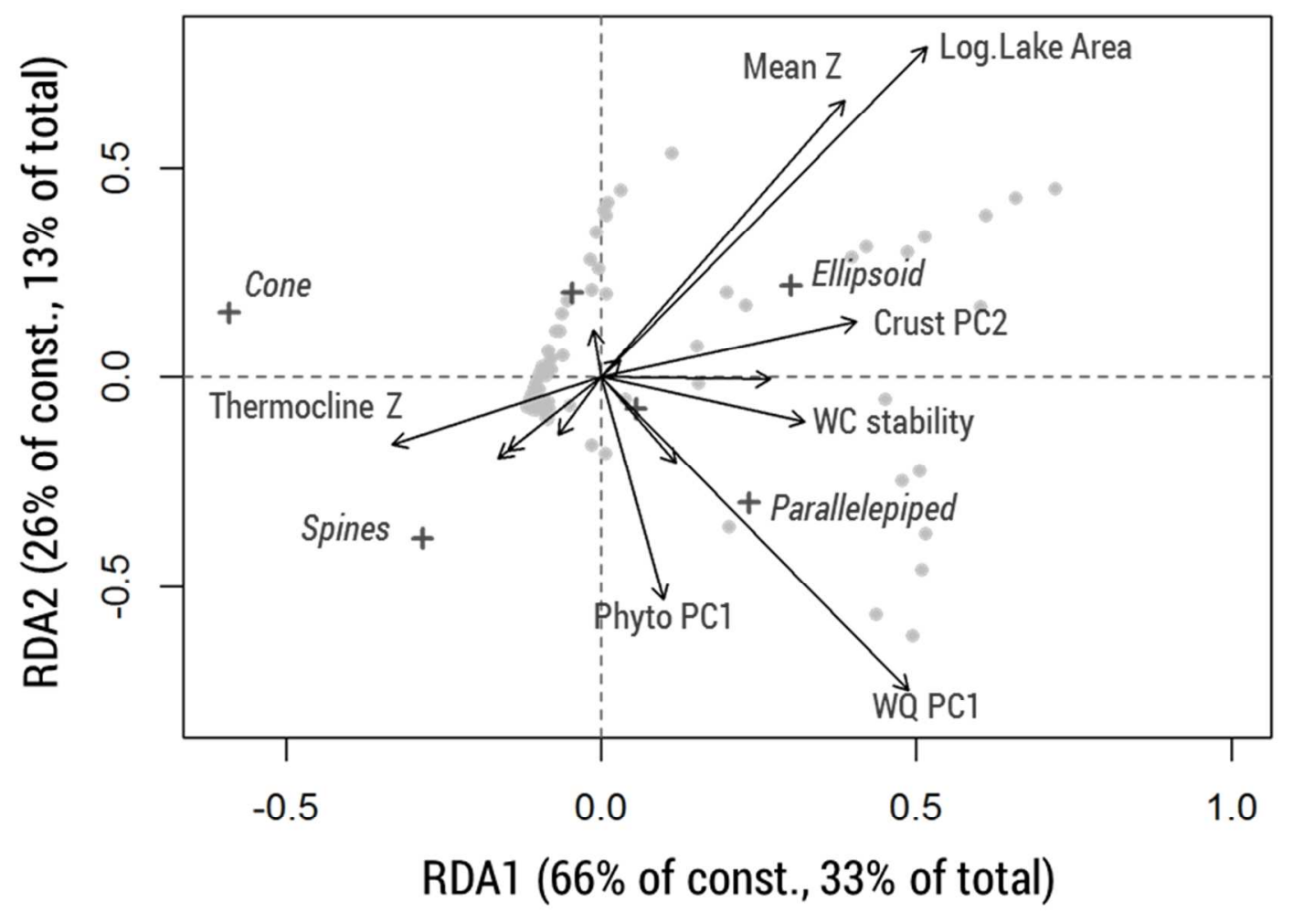

Figure 5 


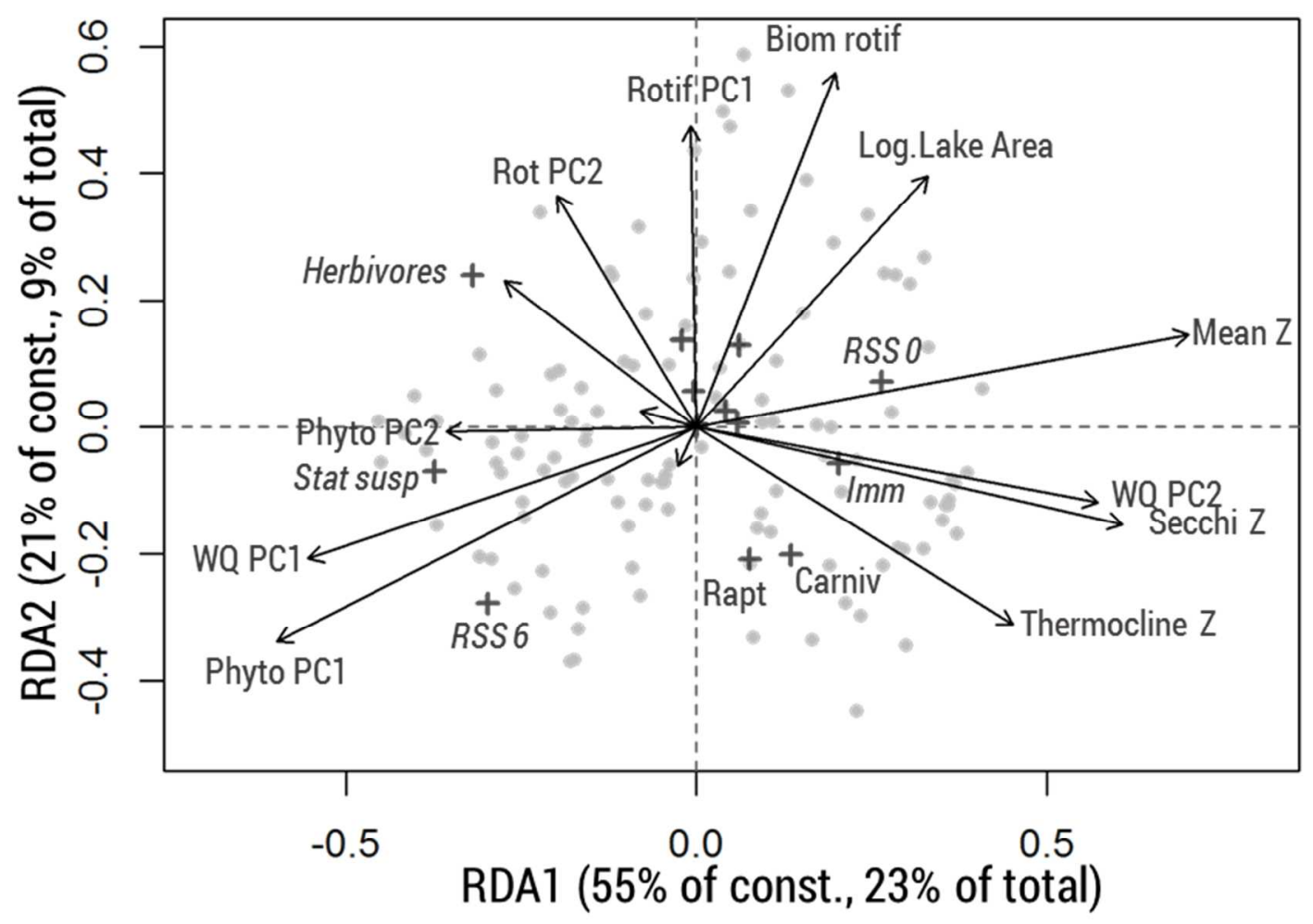

Figure 6 


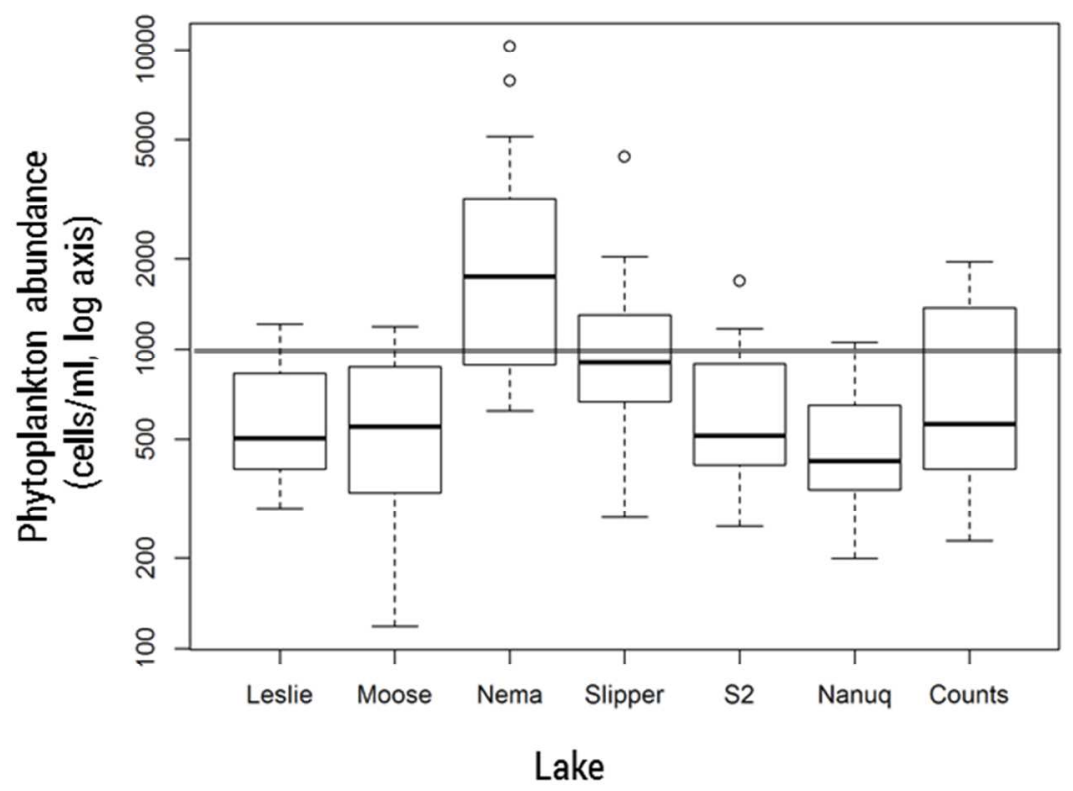

Figure 7 